\section{Report of the EMBnet AGM 2010 Workshop}

Ruvo di Puglia, June 18th, 2010
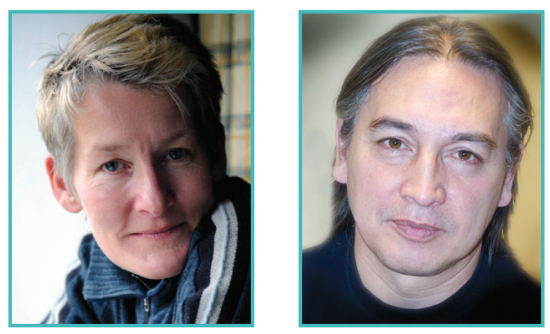

Teresa K. Attwood', Erik Bongcam-Rudloff ${ }^{2}$
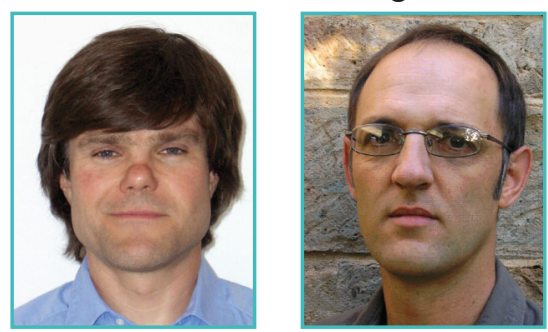

Andreas Gisel $^{3}$, Etienne de Villiers ${ }^{4}$

${ }^{1}$ Faculty of Life Sciences and School of Computer Sciences, University of Manchester, UK, 2 The Linnaeus Centre for Bioinformatics, SLU/UU, SE, ${ }^{3}$ Institute for Biomedical Technologies, CNR, Bari, IT. ${ }^{4}$ EMBnet BecA-ILRI, Nairobi, KE

\section{Executive Summary}

More than 20 years after its inception as an organisation for disseminating data, knowledge and services to support molecular biology/biotechnology research across Europe, EMBnet has arrived at a cross-roads. Since 1988, its membership has expanded outside Europe, and the nature of many of the needs it was created to support has changed. Against this background, major (government-supported) initiatives have begun to emerge to try to satisfy the modern European data infrastructure need. The 'EMBnet moving forward' workshop was an opportunity to review the current context and how EMBnet should embrace the future, to the benefit of its global membership. The following pages summarise the workshop discussions and conclusions.

\section{EMBnet structure}

This session reviewed EMBnet's structure and whether it needs more PCs or Special Interest
Groups (SIGs). The roles and aims of its EB \& PCs, its mission and USP were also explored.

\section{Conclusions:}

- no further PCs are required; the EB \& PCs will promote new activities via SIGs in future;

- roles of the EB/PCs are well defined, but new roles were proposed for the TMPC;

- SIGs with clear goals should be established and led by key individuals;

- EMBnet's mission is to share knowledge, expertise, training, etc. and should include efforts to break down barriers by seeking funding for cross-border activities;

- EMBnet's history, geographic dispersion \& multi-lingual nature are unique.

\section{EMBnet communities}

Here, we reviewed EMBnet's communities, who they are, their needs and how EMBnet should respond. We considered why people join and what they get out of it.

\section{Conclusions:}

- EMBnet's community is global \& diverse;

- community needs differ, but there are common themes: the community needs EMBnet's support to solve its local problems (IT infrastructure, tool development, training, etc.);

- EMBnet should embark on a program of activities to better serve the needs of its communities; a coordination tool to facilitate collaboration would be helpful;

- the reasons for joining EMBnet have evolved over time, but again, there are some common themes - e.g., access to support, to expertise, to standard curricula.

\section{EMBnet strategic alliances}

This session examined organisations with whom EMBnet could interact, why it should interact and the form such alliances might take. It also considered if a dedicated outreach PC was needed.

\section{Conclusions:}

- EMBnet should aim to form strategic alliances with a range of bioinformatics organisations/ networks and developer projects, and should take advantage of global funding initiatives;

- interactactions with other organisations are likely to be mutually beneficial and synergistic;

- alliances with other organisations could take different forms, depending on the aims and 


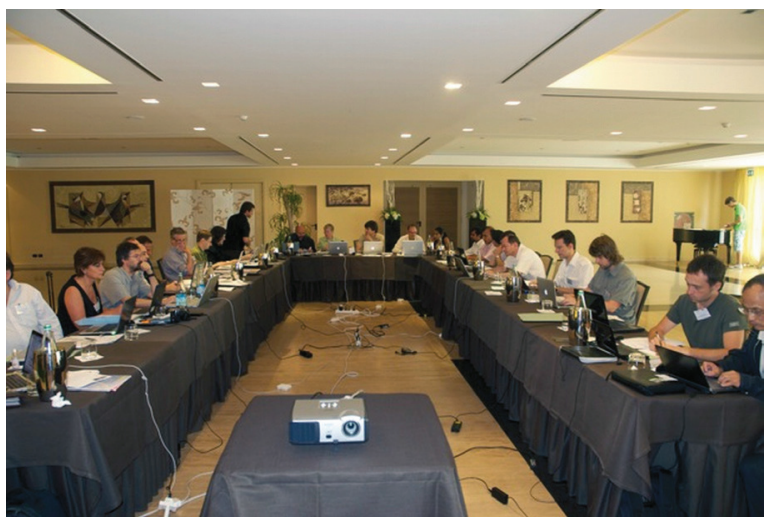

Figure 1. EMBnet AGM 2010 - Hotel Pineta, Ruvo di Puglia Bari (IT)

objectives; joint activities could be funded through mutual cooperation;

- a new outreach PC isn't needed, but a dedicated outreach member on the EB, collaborating with the P\&PR PC, could fulfill this purpose; Erik Bongcam-Rudloff is a good candidate.

\section{EMBnet.Journal}

Here, we discussed the transition to a peer-reviewed journal. We reviewed the obstacles to article submissions, strategies to overcome these, including the introduction of specific themes.

\section{Conclusions:}

- the evolution to a professional, peer-reviewed journal is a good idea;

- EMBnet.news' lack of IF and bibliographic database indexing has been a barrier;

- members would submit articles to EMBnet.journal if/when it has an IF and is registered with a bibliographic database;

- strategies for encouraging article submissions were suggested; fees need careful thought;

- specific themes were suggested, but these need to be introduced strategically.

\section{EMBnet brand}

This session examined the EMBnet brand \& what changes might be appropriate. We discussed how to improve the website \& the cost of changing it.

Conclusions:

- the name EMBnet should be retained, but it should carry a new strapline;

- the logo should remain the same;

- numerous improvements need to be made to the website; the P\&PR and PC \& TM PC need to collaborate quickly and effectively to make this happen;

- much of the work to redesign the website can be done by internally, but some aspects might need to be outsourced - these would need to be properly costed.

\section{EMBnet membership}

Here, we considered the goals and terms of personal membership, who might become personal members and whether other types of membership were needed.

\section{Conclusions:}

- the goals of personal membership are many and varied, but broadening the EMBnet constituency and building loyalties are key;

- the rights and responsibilities of personal membership should be clarified;

- the rules of personal membership need to be clarified and simplified;

- EMBnet should look into establishing Society \& Honorary memberships.

\section{EMBnet e-learning resources}

This session discussed EMBnet's e-learning resources, the kinds of materials that should be provided, how they should be kept up-to-date and their quality ensured.

\section{Conclusions:}

- EMBnet should provide a range of materials appropriate to different courses and audiences; the materials should be well structured, documented and time-stamped;

- authors should be responsible for maintaining their own content; time-stamps could be used to indicate when modules/kits were last updated;

- authors should be responsible for maintaining the quality of their own content; user feedback and satisfaction surveys should also be used;

- EMBnet would benefit from sharing its e-learning resources.

\section{EMBnet and funding opportunities}

The last session looked at funding opportunities that could support EMBnet's activities, specifically with respect to its training \& research activities and its IT projects.

\section{Conclusions:}

- numerous funding opportunities exist, which EMBnet will pursue proactively. 